\title{
La pintura de El Greco y la construcción de la historia de Toledo en el Renacimiento
}

\author{
Alicia Cámara Muñoz
}

Las vistas de Toledo que El Greco pintó en sus cuadros han sido interpretadas en alguna ocasión como visiones de la que fue la ciudad por excelencia, Jerusalén, la ciudad de Dios ${ }^{1}$. Aunque contemplar Toledo al fondo de obras de tema religioso, especialmente si se trata de una Crucifixión, justifica esta interpretación, pensamos que el Toledo que El Greco pinta, al margen de que se pueda entender simbólicamente como «nueva Jerusalén», «nueva Roma», «nueva Atenas» o incluso "nueva Troya», es el Toledo que elaboraron en sus escritos los historiadores y humanistas con los que EI Greco se relacionó en la Ciudad Imperial.

Ya durante su estancia en Roma El Greco debió tener conocimiento de la pasión erudita y anticuaria que se respiraba en lo que hoy podíamos llamar círculos intelectuales toledanos. La relación del pintor en Roma con el toledano Luis de Castilla fue, según todos los estudiosos del tema, la que le condujo a Toledo a su llegada a España. Luis de Castilla fue un hombre culto e interesado por la Antigüedad clásica, que había llegado a Roma en compañía de Pedro Chacón ${ }^{2}$. Éste último se hizo famoso en la ciudad por su conocimiento del mundo clásico y de él se decía que «supo de monedas, piedras y antigüedades Romanas más que ninguno que hasta allí vivió en Roma, y cosas que ellos no entendían se las declarava con gran claridad y facilidad " ${ }^{3}$. Chacón dejó en su testamento a su amigo

1 L. Puppl, «La città del Greco», en Actas del xxII Congreso Internacional de Historia del Arte. España entre el Mediterráneo y el Atlántico. (Granada, 1973), Universidad de Granada, 1976, págs. 400-401.

2 R.L. KAGAN, «La Toledo del Greco», en El Greco de Toledo, Madrid, 1982, págs. 62-63.

3 JERÓNIMO ROMÁN de la Higuera, Historia eclesiástica de la ciudad de Toledo escrita por Gerónimo de la Higuera... llega asta el año de 1604. vol. 9, Biblioteca Nacional (Madrid), Ms. 1293, fols. 198 y $189 \mathrm{v} .^{\circ}$. 
Luis de Castilla las obras de Varrón, Salustio, César, Tito Livio y Plinio, y "otros de letras humanas", lo que demuestra el interés por la historia de ambos personajes. Ese interés por la historia antigua se pone también de manifiesto en la biblioteca de El Greco ${ }^{4}$. Como también parece -por los libros que poseyó- que debió interesarle el tema de la ciudad ${ }^{5}$, en una época que conoce la eclosión de las historias de ciudades.

En Toledo, de donde procedían los dos estudiosos citados que se hicieron famosos en Roma, hubo a lo largo del siglo XVI otros hombres que hicieron de los estudios del mundo clásico la razón de su vida. El presente de su ciudad, al igual que estaba ocurriendo en otras ciudades de España, se pudo convertir en campo de experimentación en el que recrear las grandezas de un pasado clásico del que hablaban tanto los libros antiguos como -lo que más les fascinaba- los restos arqueológicos que se iban encontrando, objetos con los que explicar la historia, justificar teorías y debatir hasta el enconamiento sobre su validez y sus posibles interpretaciones. En Toledo el proceso de reconstrucción de su pasado fue especialmente rico, debido a la significación histórica de la ciudad a lo largo de los siglos ${ }^{6}$. Como recordaba Pedro de Alcocer en 1554 , los godos habían dado a esta ciudad título de «civitas regia, o cibdad real y de cabeça de las Españas" ${ }^{7}$, lo cual explicaba un pasado glorioso esperando a ser descubierto por la curiosidad histórica y arqueológica del presente.

Parece que el arquitecto Juan Bautista Monegro fue uno de los que mejor conocieron y más investigaron los restos de la antigüedad que quedaban en la ciudad. Tanto Francisco de Pisa ${ }^{8}$ como Jerónimo Román de la Higuera ${ }^{9}$ citan a Monegro como su informador en lo relativo a los restos e historia de Toledo en época romana, con especial insistencia en aquellos

\footnotetext{
4 F. Marias y A. Bustamante, Las ideas artísticas de El Greco, Madrid, 1981, pág. 53.

L. PuPpI, op. cit. págs. 393-405.

6 Sobre ese pasado y su repercusión en la ciudad renacentista, R. Diez Del Corral GaRnICA, Arquitectura y mecenazgo. La imagen de Toledo en el Renacimiento, Madrid, 1987, págs. 128-141.

7 P. de AlCOCER, Historia o descripción de la imperial ciudad de Toledo, Toledo, 1554, cap. XXXII, f. XXVIII.

8 F. DE PISA, Descripción de la Imperial Ciudad de Toledo, y historia de sus antigüedades y grandeza... Toledo, 1605, $f 17 \mathrm{v} .:$ : «todo lo oicho destas ruynas de edificios que ay en la vega, es el parecer de Juan Baptista Monegro, maestro mayor de obras del Rey nuestro señor, con quien lo he comunicado".

9 J. ROMÁN DE LA Higuera, op. cit., vol. 1, B.N., Ms. 1285, f. 86. Después de una prolija descripción del uhipódromo, o circo a la parte septentrional de la ciudad en la gran llanura que llamamos Vega", se refiere a su capacidad: "... y según por muchas veces considerado Juan Bautista Monegro excelente architecto de las obras de su magestad, persona de mucho juicio, era este de Toledo capaz de trece o catorce mil personas".
} 
edificios que estuvieron en la Vega. Román de la Higuera se refiere en otro momento a una información que le ha proporcionado «una persona que tiene harto conocimiento de architectura» ${ }^{10}$. No sabemos si se puede estar refiriendo al mismo arquitecto, o simplemente a alguien entendido en arquitectura, pero resulta expresivo del papel jugado por esta profesión en la investigación arqueológica de los restos del pasado.

En esa búsqueda de los cimientos clásicos de la ciudad se recurrió a todo: si Pisa comienza su historia con una relación de los emperadores de Roma que fueron «señores» de España, la historia escrita por el segundo autor citado nos va dando gran cantidad de datos - cuya coincidencia es general (y sospechosa, pero habría que saber por parte de quién) con aquellos que aporta Pisa - sobre las ruinas que se iban hallando y las interpretaciones que se daban al respecto: los restos de edificios que se encontraron cerca de Santa Leocadia "de fuera" que habían hecho pensar a algunos que la ciudad había sido edificada al principio allí, en la Vega, las covachuelas que quedaban del teatro romano cerca del Hospital Tavera, las hipótesis sobre dónde estuvo el templo de Hércules, los restos de un edificio que parecía de época romana para conducir el agua a la ciudad y que estaba junto al puente de Alcántara...

Toledo no sólo tenía una puerta que debía su nombre a los romanos, como era la de Bisagra - «el nombre propio que hasta oy tiene una de las puertas principales desta ciudad a que ellos pusieron nombre de Via Sacra, que ahora corrompido el vocablo llamamos de Visagra" ${ }^{11}$ escribía Pisa siguiendo a Alcocer ${ }^{12}$ - sino que tenía "siete montes o collados" «que parece Toledo tener alguna semejança con Roma y en esto ser como un rrasguño suyo» ${ }^{13}$. Lo forzado de las comparaciones, que podían

10 J. ROMÁN dE LA HIGUERA, op. cit., vol. 3, B.N., Ms. 1287, f. 129. Escribiendo sobre si San Eugenio y San Heladio (sic) estarían enterrados en la capilla de San Ildefonso, dice que «una persona que tiene harto conocimiento de architectura me dixo que abriendo un hoio por un lado de la hermita de $\mathrm{S}$. Ildefonso avía visto en un gueco que alí se hacia, unos como pilares que parecía sustentaban un sepulchro, quizá es alguno de los sanctos...»

11 F. de PISA, op. cit. (1605), f. 17.

12 P. DE AlCOCER, op. cit., cap. XVI, f. XIX. Agradezco al profesor V. Nieto la indicación sobre las citas de Alcocer.

13 J. ROMÁN DE LA HigueRA, op. cit. (B.N., Ms. 1285), f. 119 y 120: «... y subiendo desde el arrabal haçia Çocodover el primer collado, es el que se hace en el varrio de la Caveça del aguila que llega hasta Çocodover. Luego viene otro cerro, o collado que llega asta el alcaçar cuyas vertienes son a S. Miguel donde dicen el espinar del can. Luego viniendo desde el espinar al río por el Alhandaque beniamos a dar a otra altura y llano donde está la Yglesia mayor. El quarto es como venimos a dar a $\mathrm{S}$. Andrés, el quinto a $S$. Román, el sexto es el que decimos montechel y el alamillo de $S$. Cristoval otro es de la puerta del cambrón puente de san Martín hasta la solana de san Juan de los rreyes que parece Toledo tener alguna semejança con Roma y en esto ser como un rrasguño suyo". 
incluso violentar la geografía (¿y si lo hacían los historiadores, tan pretendidamente objetivos, por qué no lo iba a hacer El Greco en esa Vista de Toledo que tanto ha impresionado por su «subjetivismo» y su apariencia de recreación onírica de la ciudad?) no debe hacernos olvidar que esa fue la imagen de Toledo que quisieron construir los eruditos toledanos: una ciudad que compendiaba la historia de España y que hundía sus raíces en el mundo clásico, hasta el punto de que, incluso en su presente, conservaba rasgos urbanos que la hacían comparable con la antigua Roma. Puede no sorprendernos que se compare la plaza mayor con el «forum maius" de Roma, a los cigarrales con "los pretorios y villas urbanas de los Romanos", o la llanura de la Vega con el "Campo marcio», pero no deja de ser curioso y un ejemplo de manipulación histórica por parte de alguno de estos eruditos el que uno de los más graves problemas de la ciudad como era el de su urbanismo se compare también con el de la Roma clásica, donde hubo «angripportus acá callejones que no tienen salida» ${ }^{14}$.

El texto de Román de la Higuera nos da algunos ejemplos de la comunicación que existió entre los hombres que hicieron de la investigación histórica su objetivo, y de cómo corrían las noticias. Refiriéndose a una antigua fuente, escribe que el año anterior le había dicho «Vocangel, muy grande Sr., y amigo mío, que le dixo el maestro Alvar Gómez, que le avían enviado una escritura de flandes donde se decía que avía sido aquella fuente muy estimada en tiempo antiguos». También sabemos que este jesuita fue presentado al cronista de Aragón, Jerónimo Blancas, por Antonio de Covarrubias, para que le aclarara sus dudas sobre el Itinerario de Antonino ${ }^{15}$.

Más interesante, por la relación que podría tener con una de las imágenes de Toledo pintada por El Greco, es la noticia que da referida al puente de Alcántara, junto al cual había en ese tiempo restos de un gran edificio de tiempos de los romanos para conducir el agua a la ciudad. Nos cuenta que el licenciado Castillo, médico granadino y gran conocedor del árabe, le había escrito para contarle que, en un libro de la Biblioteca de El Escorial encontró «como los moros desta ciudad tenían en lo alto deste conducto un artificio lunar que tenía de Relox de noche quando havía luna como nos servimos de los de sol entre día» ${ }^{16}$. Un reloj que hubiera podido

14 J. Román de la Higuera, op. cit. vol. 1, B.N., Ms. 1285 , f. 99 y 120 v. ${ }^{\circ}$

15 La cita en Idem,vol. 3, B.N., Ms. 1287, f. 150. Sobre la relación de J. ROMÁN con A. DE COVARRUBiAS, véase G. DE ANDRÉs: «El helenismo del canónigo toledano Antonio de Covarrubias. Un capítulo del humanismo en Toledo en el siglo xvi». Hispania Sacra, vol. 40, 1988, pág. 277. G. de Andrés pone en duda el rigor histórico de J. ROMÁN DE LA HIGUERA en lo referente a la historia eclesiástica hispana.

16 J. ROMÁN DE L.A HIGUERA, idem, f. 128 y 128 v.. 


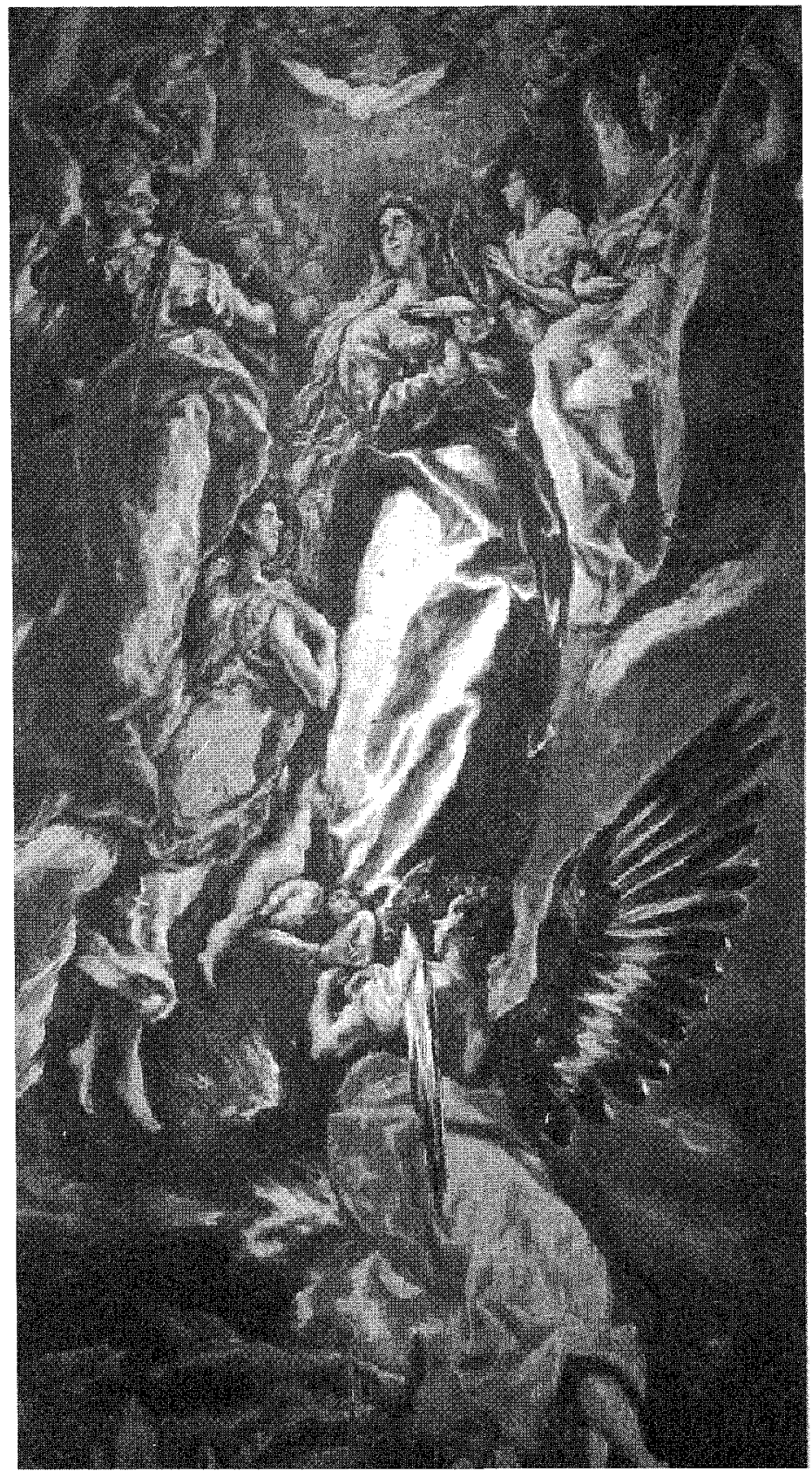

Fig. 1. El Greco. La inmaculada Concepción. Toledo. Museo de Santa Cruz. 
dar la hora de la Vista de Toledo pintada por El Greco hacia 1600, iluminada por unas luces tan irreales y soñadas como las que sólo la noche permite imaginar.

En la vista de Toledo que el pintor representa en la La Asunción del Museo de Santa Cruz —que ya Wethey consideró una Inmaculada Concepción, y refrendó Stratton que se refiere a ella como «una versión enérgica de la familiar Virgen tota pulchra del siglo XV|» ${ }^{17}$-aparece un edificio sobre el puente, que ha sido razonablemente interpretado como la Puerta del Cielo ${ }^{18}$. Sin embargo, aventurando hipótesis sin duda difíciles de probar ¿no podría ser ese edificio del que hablaba el libro de El Escorial, junto al puente de Alcántara, con su reloj lunar, el que El Greco quiere representar, sustituyendo a la luna como atributo mariano por un reloj lunar en el nocturno henchido de historia de la ciudad de Toledo? Acerca de la visión nocturna en esta obra de El Greco cabría hacer otra observación, basándonos en este caso en un escrito del que fue uno de sus mejores clientes, Pedro Salazar de Mendoza, que también fue un erudito historiador. En la historia que escribió de San Ildefonso recordaba cómo una de las excelencias de la iglesia toledana era la de «llamarnos a Maytines a media noche; cosa de que nuestro Señor deve ser muy servido, pues quiso fuesse a esta hora la descensión de la beatissima Virgen», y, efectivamente, cuando relata el milagro de la aparición de la Virgen a San Ildefonso, recuerda que fue a la hora de maitines, que era la media noche ${ }^{19}$. Teniendo en cuenta que la Virgen se apareció a San lldefonso por haber sido este santo uno de los grandes defensores de su pureza, parece lógico que la iconografía del cuadro de El Greco sea la de la Inmaculada Concepción, en la hora nocturna de la aparición al santo en la ciudad de Toledo. Por eso no es la Virgen apareciéndose al santo para imponerle la casulla, sino la imagen de la Virgen que ese santo contribuyó a crear.

El autor cuyo texto estamos siguiendo, Jerónimo Román de la Higuera, fue uno de los expertos reconocidos en antigüedades romanas en la Toledo que vivió El Greco. Cuando, a punto de finalizar el siglo, excavando en los cimientos de las casas que se habían derribado cerca de la plaza mayor para hacer el Hospital del Rey, se encontraron los restos de un templo

\footnotetext{
17 S. Stratton, «La Inmaculada Concepción en el arte español», Cuadernos de Arte e Iconografía, tomo I, n² 2, segundo demestre de 1988, pág. 47.

$18 \mathrm{~J}$. BROWN y R. KAGAN, "La Vista de Toledo», en J. BRown y otros, Visiones del pensamiento. El Greco como intérprete de la historia, la tradición y las ideas, Madrid, 1984, pág. 52.

19 P. Salazar de Mendoza, El glorioso doctor san llefonso, arçobispo de Toledo, Primado de las Españas. Toledo, 1618. F. d2v. ${ }^{\circ}$ y pág. 79.
} 
antiguo y un osario, se pensó que allí había estado la iglesia de San Tirso, pero sería este jesuita quien lo confirmaría: en las excavaciones encontraron la tapa de un aguamanil con las letras $\mathrm{C}$ y $\mathrm{S}$, que «andava de mano en mano, y desseavase entender la cifra. Vino a noticia de un padre de la Compañía de Jesús, persona curiosa, y que avía juntado muchos papeles, porque escrivía una historia de Toledo, siendo natural desta ciudad: el qual viendo la cifra del tapador, mostró una carta en lengua latina, que él tenía, y afirmava averla copiado de un libro antiguo". Se trataba de una carta del rey Silo a Cixila, arzobispo de Toledo, que probaba que el edificio hallado en las excavaciones sería el templo dedicado por Cixila a San Tirso, y que luego destruirían los moros al hallarse tan cerca de su mezquita. Eso produjo al parecer gran conmoción en la ciudad, pues "yvan unos y bolvían otros a ver el templo arruynado, y desseavan se tornasse a edificar, y ganar la intercession de este santo martyr, añadido de nuevo a los demás que tienen a cargo esta ciudad" ${ }^{20}$. Como podemos comprobar con esta historia, el rastreo no era sólo la búsqueda de un pasado clásico, sino también la búsqueda de santos y mártires, destinados a convertirse en patronos y protectores de la ciudad. Así quedará también reflejado en la pintura de El Greco, como vamos a ver.

En las dos vistas más famosas de la ciudad pintadas por El Greco, aquellas que no aparecen como fondo de otros temas, sino como protagonistas del cuadro ${ }^{21}$, podemos ver convertida en imagen la historia de la ciudad, de acuerdo con los modelos literarios que constituyeron el entramado de todas las historias de ciudades escritas en los siglos XVI y XVII ${ }^{22}$ : la antigüedad clásica, los santos protectores de la ciudad, los edificios con valor histórico, los nuevos edificios, y la renovación urbana en aquellas ciudades en las que ésta se había producido.

Se da en estas obras un interesante paralelismo entre pintura y literatura, pues El Greco nos «pinta» una historia de la ciudad de Toledo, lo mismo que Francisco de Pisa y Jerónimo Román de la Higuera hicieron con la palabra. Pisa publicó en 1605 su historia de Toledo, de la Higuera

20 Traslado de la carta y relación que embió a su Magestad, el señor don ALONSO DE CARCAMO, Corregidor de la Imperial Ciudad de Toledo, acerca del Templo que en ella se ha hallado, el señor san Tyrso (Toledo, 1595). B.N., Ms. $n^{\circ} 1317$, fols. 429, 435, y 435 v. ${ }^{\circ}$.

${ }_{21}$ Sobre las vistas de Toledo pintadas por EL GRECO, J. Brown y R.L. KAGAN, "La "Vista de Toledo" ", en J. Brown y otros, 1984, págs. 37-55. Hace ya tiempo que fue señalado el interés de EL GRECo por el tema de la ciudad, tanto por sus pinturas como por los libros que tuvo en su biblioteca: L. PuPPI, op. cit., págs. 393-405.

22 Sobre el tema de las historias de ciudades y la imagen urbana, A. CAMARA, Arquitectura $y$ sociedad en el Siglo de Oro. Idea, traza y edificio, Madrid, 1990. 
escribía su primer tomo en 1595 - según dice él mismo en sus páginasy el último llega hasta 1604. La primera Vista de la ciudad pintada por El Greco se viene fechando últimamente hacia 1600, y la Vista y plano de Toledo se data hacia 1610-1614. Según Marañón -luego corroborado por todos los estudiosos del tema - fue Francisco de Pisa uno de los amigos del pintor, $e$ incluso se ha apuntado la hipótesis de que le pudiera haber servido de modelo para alguno de los santos de sus cuadros ${ }^{23}$. De su posible relación con el jesuita no se tienen datos, pero como veremos fue un hombre lo suficientemente conocido en la ciudad (él y sus teorías) como para que El Greco supiera de él y de la historia de Toledo que estaba escribiendo.

En la obra de El Greco Vista y plano de Toledo la Virgen desciende con los ángeles del cielo para imponerle la casulla a san Ildefonso, patrono de la ciudad y por tanto su protector. En todas las historias de ciudades, la referencia a sus santos protectores era obligada. En el caso de Toledo y san Ildefonso, Pisa indicaba en su historia que, si le dedicaba más páginas que a otros era «por la singular devoción que los Toledanos somos obligados a tener de nuestro gran prelado, patrón, y abogado» y El Greco representa sobre la ciudad a la Virgen, cuya pureza y virginidad habían sido defendidas por el santo, en su aparición a éste «trayéndole por sus manos la vestidura de los tesoros del cielo", tal como relata Pisa ${ }^{24}$.

La referencia al mundo clásico, que nunca falta en las historias de las ciudades del Renacimiento, la vemos en la pintura de El Greco en cómo representa al río Tajo, personificado al igual que se había hecho con los grandes ríos de la Antigüedad. También en este caso son las historias de Toledo las que nos aportan toda una serie de informaciones que explican el por qué de este motivo. El hecho de que se trate de un joven se podría relacionar con la cita que hace Pisa de Alvar Gómez de Castro -autor del texto que explica la historia del Entierro del conde de Orgaz bajo la obra- quien, después de celebrar las fuentes de la ciudad escribió que, como en invierno «entra el río por val de Colomba... finge poéticamente el dicho autor, que el río Tajo a manera de un galán, enamorado de val de Colomba, como de su dama y amiga, la va a visitar por aquellos tiempos» 25 .

Alvar Gómez de Castro fue uno de los humanistas más famosos -ya

23 J. GOMEZ-MENOR FUENTES, estudio preliminar a la obra de F. DE PISA, Apuntamientos para la Il parte de la "Descripción de la Imperial Ciudad de Toledo", Ed. de Toledo, 1976, págs. 17 y 18.

24 F. DE PISA, Descripción de la Imperial Ciudad de Toledo, $y$ historia de sus antigüedades y grandeza... Toledo, 1605 , fols, 100 y $106 \mathrm{v} .^{\circ}$

25 Idem, fol. $15 \mathrm{v}^{\circ}$. 


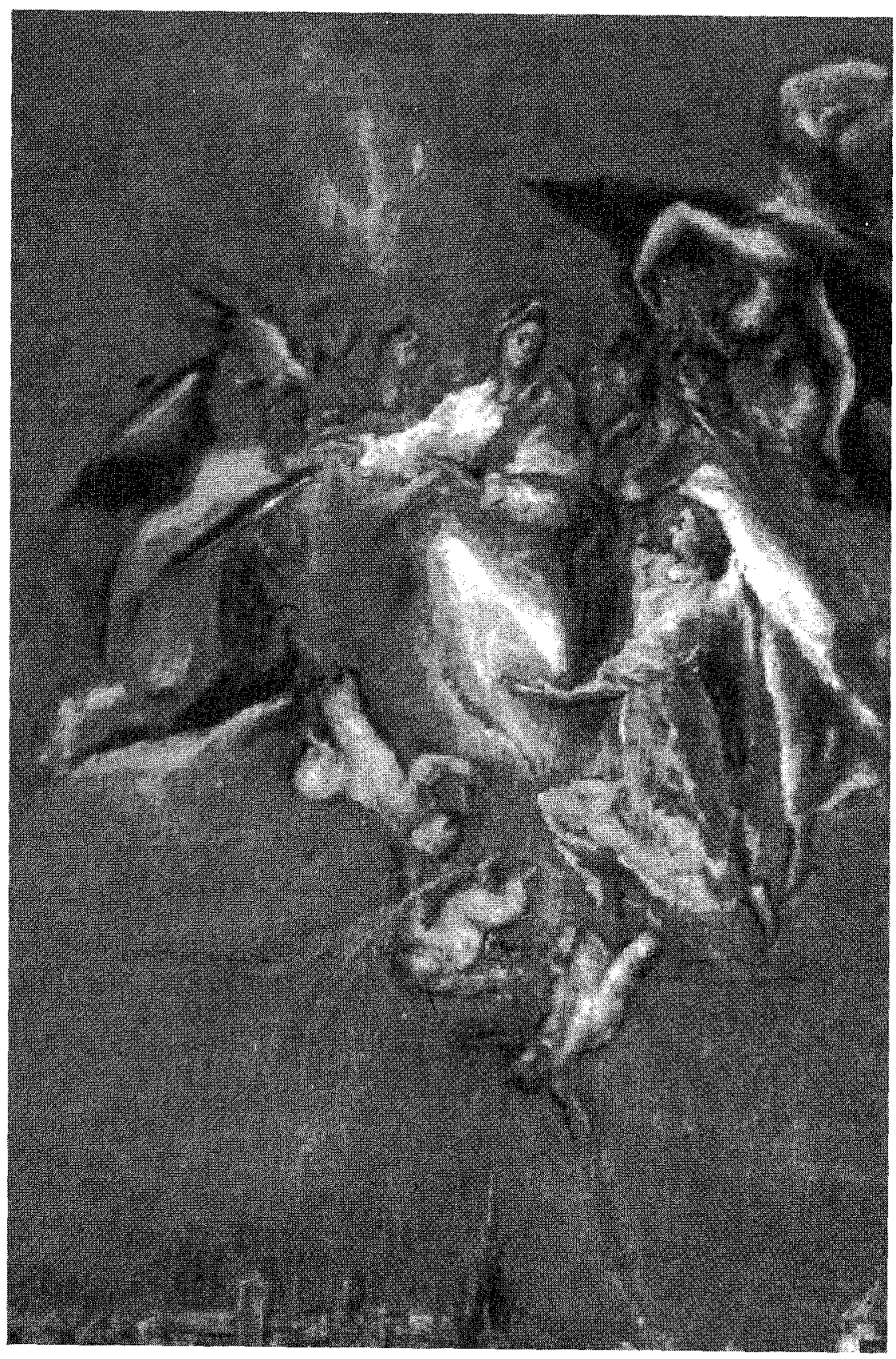

Fig. 2. El Greco. Vista y plano de Toledo (Detalle). Toledo, Museo del Greco. 


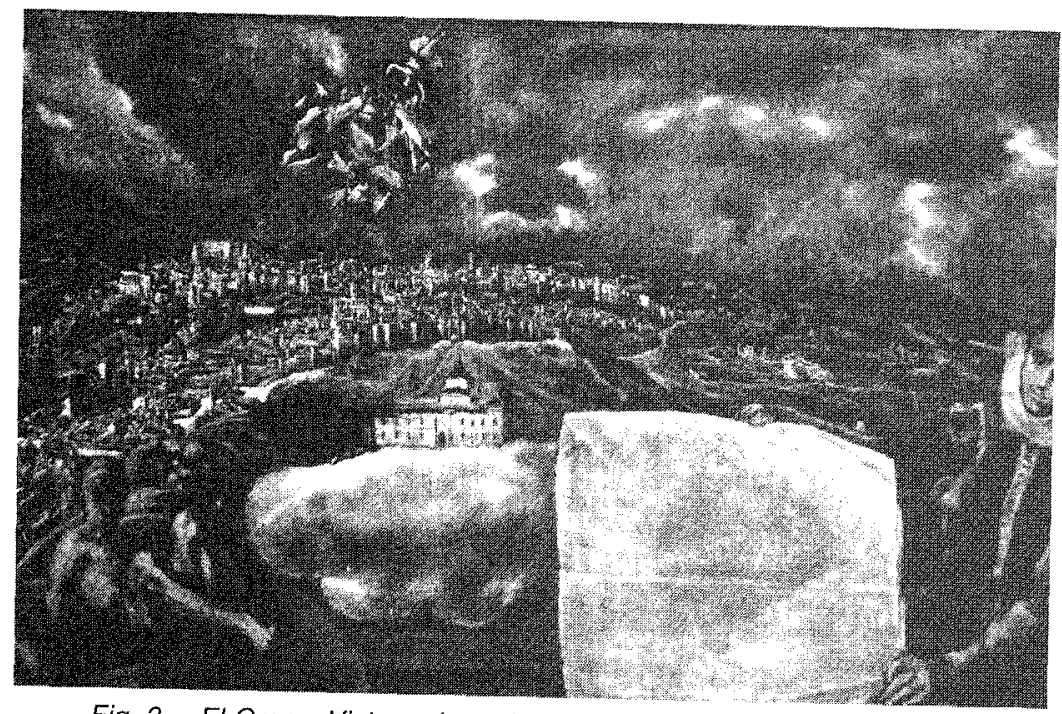

Fig. 3. El Greco. Vista y plano de Toledo. Toledo, Museo del Greco.

en vida- del Renacimiento español. De él escribio Jerónimo Román de la Higuera, a comienzos del siglo XVII, que tenía su casa en Toledo llena de "elegantes inscripciones al husso Romano", que "vio muchos papeles desta ciudad y dello hiço un libro que llamo de fragmentos» y que «tutuvo conocimiento de las antigüedades de los Romanos y de las desta ciudad» ${ }^{26}$. Aunque hoy día sabemos mucho más de Alvar Gómez de Castro, esta cita es significativa por la cercanía en el tiempo y la referencia a lo toledano y a ese ambiente de erudición y de investigación histórica con respecto a la antigüedad en el que también se debió mover El Greco.

La personificación de los ríos fue frecuente en el siglo XVI con ocasión de las Fiestas, cuando cada ciudad quería perpetuar una imagen determinada de sí misma - como harán, con otros medios, El Greco y los historiadores con Toledo-, uno de cuyos componentes era siempre el de la Antigüedad clásica: el río Betis tomó forma de coloso para recibir a Felipe II en Sevilla en $1570{ }^{27} \mathrm{y}$, en el ámbito toledano, para la entrada triunfal de isabel de Valois en Alcalá de Henares en 1560, el río Henares adoptaría la

26 Historia de la ciudad de Toledo escrita por Gerónmo de LA HIGUera... llega asta el año de 1604. Biblioteca Nacional (Madrid), Ms. 1293, f. $185 \mathrm{v}{ }^{\circ}$.

${ }^{27} \mathrm{~V}$. LLEÓ, Nueva Roma: Mitologia y Humanismo en el Renacimiento sevillano. Sevilla, 1979 , pág. 175 . 
forma de un viejo ${ }^{28}$. En otras fiestas anteriores en la misma ciudad, para celebrar la llegada a Alcalá del cardenal Juan Martínez Silíceo en 1546, el humanista Alvar Gómez de Castro escribió Publica Laetitia, uno de cuyos emblemas representaba al río Tajo como un anciano ${ }^{29}$, y como un anciano aparecía también en las entradas triunfales en Toledo. El carácter abocetado de la figura pintada por El Greco no permite asegurar que se trate de un joven, pero mucho menos de un anciano que, como hemos visto, era lo normal, pues la musculatura, la cabeza y los rasgos que se adivinan más parecen transmitir una imagen de juventud, lo cual se podría relacionar con el texto de Alvar Gómez de Castro recogido por Pisa.

La forma en que se le representa es, además, exactamente la misma que le dieron en uno de los arcos triunfales realizados para el recibimiento en Toledo de Isabel de Valois y que conocemos precisamente gracias al libro que sobre esta entrada triunfal escribió Alvar Gómez de Castro: «levantado el medio cuerpo sobre un cántaro, de donde parecía que derramaba agua afirmando la una mano sobre él, y en la otra tenía un cornucopia, poblado de mucha fruta" ${ }^{30}$. La diferencia es que en ese caso se trataba de un viejo y, en cambio, en la obra de El Greco es un joven, aunque la fuente de autoridad parezca ser el mismo escritor.

El hecho de que aparezca figurado como si fuera de oro se explicaría también por lo relatado tanto por ese autor como por otros, pues, en las fiestas citadas en Toledo, el Tajo recibió a Felipe II «offreciendo a la magestad del Rey nuestro señor sus arenas doradas " ${ }^{31}$. Jerónimo Román de la Higuera habla del "Dorado y celebradissimo Tajo» que llevaba «en su corriente Rieles de oro fino" ${ }^{32}$. Sobre esta característica, recordaba Francisco de Pisa que, según hicieron constar los escritores de la Antigüedad, era un río de aguas doradas, por llevar arena de ese metal precioso. El texto de Pisa es el que sigue: «Este famoso Río es muy celebrado por los historiadores y poetas antiguos, assi como Plinio, luvenal,

28 Relación del recibimiento que la Universidad de Alcalá de Henares hizo a los reyes... Alcalá de Henares, 1560. Publicada por J. Simón Díaz, Fuentes para la historia de Madrid y su provincia. I, Madrid, 1964, págs. 1 y ss.

29 P. Martínez-Burgos Garcia, «Publica Laetitia, Humanismo y Emblemática (la imagen ideal del Arzobispo en el siglo XVI». Cuadernos de Arte e lconografía, 1. I, no 2, 1988, pág. 136.

30 Alvar Gómez dE CASTRo, Recebimiento que la Imperial Ciudad de Toledo hizo a la magestad de la Reyna nuestra señora doña Ysabel, hija del Rey Henrrico Il de Francia: quando nuevamente entro en ella a celebrar las fiestas de sus felicissimas bodas, con el Rey don Philippe nuestro señor li destre nombre. Toledo, 1561, f. 38.

31 Idem, f. 27 v. ${ }^{\circ}$.

32 J. Román de la Higuera, op. cit., (B.N., Ms. 1285), f. 215 y 215 v. ${ }^{\circ}$. 
Ovidio y Marcial, los quales escriven del que lleva arenas de Oro Pomponio Mela libro 4 de Situ orbis capítulo I dize que este Río engendra oro y piedras preciosas. Marcial en un Epigrama que haze a Licinio dize assi. A estus serenos aureo franges Tago/Obscurus umbris Arborum. Como si dixera, podrás quebrantar los ardores del Estío con las aguas del dorado Tajo, y defenderte con las sombras de los árboles» ${ }^{33}$. Las mismas fuentes clásicas citaba años más tarde Tirso de Molina al recrear la imagen de Toledo, en la cual «el nunca suficientemente alabado Tajo, incansable rondador de su belleza, retratando en el oro potable de su cristal las luminarias, daba más quilates dél a sus arenas y materia más copiosa a los versos de Marcial, Ovidio y Juvenal, para celebrarlas" ${ }^{34}$.

El joven Tajo de oro del cuadro pintado por El Greco resulta así ser una imagen construida en aquellos círculos eruditos toledanos con los que el pintor se relacionó, y de los que fueron partícipes activos tanto Alvar Gómez de Castro como Francisco de Pisa ${ }^{35}$. Incluso el empeño de éste último por resaltar en su historia cómo en Toledo «se ha trabajado y tenido cuydado de repararla, y ensanchar y desenfadar las calles, dexando desocupadas en lugares públicos muchas plaças...", se podría poner en relación con el famoso plano de la ciudad que incluye El Greco en su vista, en el que ese importante proceso de modernización a que fue sometida la ciudad está ya incorporado.

La historia de Francisco de Pisa se publicó cuando la corte había dejado Madrid para instalarse en Valladolid, es decir, cuando todavía no estaba suficientemente claro en qué ciudad acabaría asentándose definitivamente. De las mismas fechas dataría la ya citada historia manuscrita del jesuita Jerónimo Román de la Higuera, que llega hasta el año 1604 y en la que se declara discípulo de Francisco de Pisa, «perssona de muchas letras y aprobada vida... devole yo esta memoria en señal del agradecimiento que deven los reconocidos Discípulos a sus Maestros» ${ }^{36}$. Tanto la segunda parte de la historia de Pisa, como la Vista y plano de El Greco,

33 F. de Pisa, 1605, f. 15

34 Tirso de Molina, Cigarrales de Toledo (1621), Ed. de Madrid, 1968, pág. 15.

35 Sobre los personajes toledanos con quienes se relacionó $E_{L}$ GRECo, bien por trabajo, bien por amistad, R.L. KAGAN, «La Toledo del Greco», en El Greco de Toledo, Madrid, 1982 y F. MaRIAS y A. Bustamante, Las ideas artisticas de El Greco, Madrid, 1981, especiaimente págs. 199-202.

36 J. ROMÁN DE LA HIGUERA, op. cit., f. 191. No he encontrado datos sobre la posible rivalidad entre los dos historiadores, salvo lo que se cita unas páginas más adelante acerca del monasterio Agaliense. Da que pensar, no obstante, que los nueve tomos manuscritos de DE LA HIGUERA quedarán sin publicar y acaben inmediatamente antes de que PISA diera su libro a la imprenta. Parece tan forzado el elogio del jesuita a "su maestro", que es posible que para entonces ya se estuviera viendo él en el olvido y a PISA eternizado por la imprenta. 
son ya posteriores a la vuelta de la corte a Madrid, pero podrían ser vistos como el resultado final del empeño de muchos toledanos por que la corte volviera a la ciudad, modernizada en su arquitectura y urbanismo y cuya grandeza incontestable databa de la antigüedad clásica. Han sido Brown y Kagan ${ }^{37}$ quienes han relacionado las vistas de Toledo pintadas por El Greco con la persona de Pedro Salazar de Mendoza quien, además de esta obra, parece que poseyó también la Vista de Toledo pintada hacia 1600. Fue este hombre, administrador del Hospital Tavera, uno de los paladines del empeño en que la corte volviera a Toledo ${ }^{38}$.

En la vista y plano se destaca especialmente el Hospital Tavera, obra fundamental para la arquitectura del Renacimiento español, de la que era administrador el citado Salazar de Mendoza. Este edificio está situado sobre una nube, a modo de maqueta - «modelo» 39 lo llama El Greco en la inscripción explicativa-y desplazado del lugar que ocupaba realmente, para no interferir así la vista de la ciudad según explicación del pintor. Ese extraer de la ciudad los edificios más representativos para reforzar con su imagen la grandeza de una ciudad que, a la vez, podía ser contemplada en su conjunto se había hecho ya en un grabado anterior de Toledo (con la catedral y el alcázar), destinado a tener mucha difusión ${ }^{40}$ y fue un método empleado también por los historiadores de las ciudades en el Siglo de Oro, que destacaban en el relato la magnificiencia de los edificios más representativos.

Así lo hizo Alvar Gómez de Castro al escribir que, cuando Isabel de Valois llegó a la vista de Toledo «havía principalmente dos hedeficios: los quales entre los otros muy a la clara se señalavan: mostrando bien desde lexos a los que vienen: el señorío y magestad de la ciudad. El uno es el alcaçar aposento de los reyes cercado de muy fuertes y grandes torres. El otro es el templo principal de esta Ciudad, cuya Torre tiene forma de Pyramis, muy alta y de

37 J. Brown y R.L. Kagan, «La Vista de Toledo», en J. Brown y otros, Visiones del pensamiento. Estudios sobre El Greco. Madrid, 1984, págs. 39-55.

38 Sobre este personaje, así como sobre la relación entre Toledo y la corte (rechazo, actuaciones emprendidas para que volviera...), véase R.L. KAGAN, «La Toledo del Greco», en El Greco de Toledo, Madrid, 1982.

39 En el Tesoro de la lengua castellana, o española de S. CovarRuBIAs, Madrid, 1611, el término MODELO significa Latine exemplar vel archetypus, como para hazer una torre o otro edificio el artífice. Armase toda aquella fábrica abreviada en una pieça pequeña, que della a la principal no huviesse más diferencia que sólo el tamaño, o al revés, si de un gran edificio quisisesse hazer el dicho modelo".

40 Se trata del grabado de Hoefnagel, Vista de Toledo (1566), para la obra de Braun y Hogenberg Civitates Orbis Terrarum, que fue uno de los libros que probablemente poseyó El Greco. F. Marias y A. Bustamante, Las ideas artísticas de El Greco, Madrid, 1981, pág. 53. 
mucha obra" ${ }^{41}$. Lo mismo que hace este humanista con la palabra, lo hizo Hoefnagel en el grabado a que hemos aludido poco tiempo después y, muchos años más tarde. El Greco llegó a modificar en su Vista de Toledo la ubicación de la catedral precisamente para que ambos edificios aparecieran en la imagen. El Alcázar de Toledo, como ha señalado V. Nieto, se convirtió en el Renacimiento en «un monumento símbolo», «un objeto figurativo que representa la idea del Templo Palacio de la Paz: alegoría de la restauración y fortaleza de una monarquía que vió truncada en Toledo su trayectoria» ${ }^{42}$. El carácter simbólico de este edificio, en una visión histórica que trasciende la propia historia de la ciudad, para convertirse en emblema de la monarquía, se convierte en imagen en la obra de El Greco, que lo sitúa coronando toda la sucesión de edificios en los que se compendía la historia de Toledo, que había sido, a su vez, privilegiado escenario de la historia de España.

Volviendo a las historias de las ciudades, cuya estructura argumental se oculta en las pinturas de El Greco, unas veces habia sido la antigüedad de sus piedras lo que había conferido a los edificios que historiadores y pintores singularizaban en sus obras ese valor histórico, pero otras veces fueron los edificios nuevos o renovados los que merecieron ser destacados en estas historias escritas o pintadas. En el caso de la Vista y plano de Toledo, el Hospital de San Juan Bautista de Afuera era un edificio nuevo que compendiaba la renovada imagen arquitectónica de la ciudad. Su soberbio aislamiento en una nube y el hecho de que El Greco lo moviera en su cuadro como se mueve una maqueta o "modelo", para así mostrar su fachada, lo convierten en arquetipo, en un complejo arquitectónico tan perfecto en sí mismo, en su soledad, como el que nos transmitirán las imágenes del monasterio de El Escorial por los mismos años ${ }^{43}$.

La nueva Toledo, que se reconocía en esta obra con la que emulaba las grandezas de la Antigüedad ${ }^{44}$, edificada además en la zona donde quedaban más restos del mundo clásico, cuyas piedras se utilizaron para la construcción ${ }^{45}$, tenía también otro rico pasado, en ese caso además

\footnotetext{
41 A. Gómez de Castro, op. cit., f. 12 v..

42 V. Nieto AlCAIDE, "El mito de la arquitectura árabe, lo imaginario y el sueño de la ciudad clásica». Fragmentos, revista de arte. n 8-9, 1986, págs. 140 y 141

43 Entre los libros de El Greco estuvo el Sumario y Breve declaración de los diseños y estampas de la Fábrica de San Lorenzo el Real del Escurial, de 1589. Idem, pág. 50.

${ }_{44}$ F. MARIAs ha relacionado su planta con la casa romana del texto de VITRUVIO, en la edición de Fra Giocondo, La arquitectura del Renacimiento en Toledo, Toledo, 1983, I, págs. 233 y ss.

45 J. ROMÁN DE LA HIGUERA, Op. cit., vol. 3, B.N., Ms. 1287, f. 148: «porque alli hay grandes piedras y cimientos de edificios grandes, de donde se sacó toda la piedra para el edifiçio, y magnífica fábrica del hospital de Illmo. Cardenal y Arçobispo de Toledo..."
} 
santificado. Quizá por eso, lo mismo que en esta Vista y plano el Hospital se sitúa sobre una nube, en la Vista de Toledo pintada unos años antes, hacia 1600, es el monasterio agaliense - seguimos la hipótesis de Brown y KAGAN ${ }^{46}$ - donde vivió San lldefonso, el edificio que aparece sobre una nube. Los autores citados han considerado que se dan unas ciertas analogías entre ambos edificios, pero, independientemente de ello, es de nuevo la historia de Francisco de Pisa la que nos puede dar alguna nueva

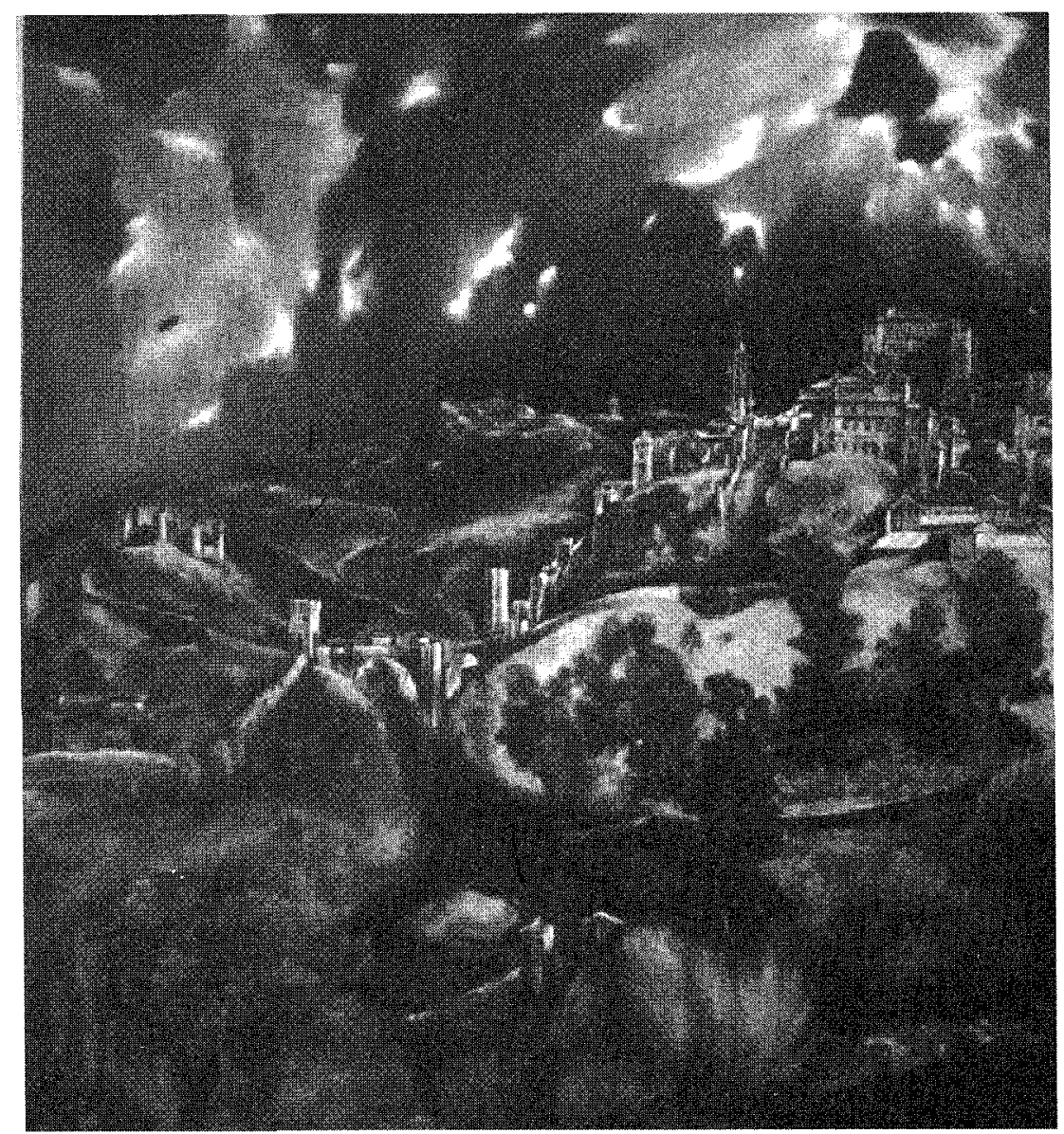

Fig. 4. El Greco. Vista de Toledo. Nueva York. The Metropolitan Museum of Art.

46 Brown y KagAN, op. cit., págs. 50-51. 
clave sobre ese edificio, creemos que acertadamente identificado con el monasterio agaliense. Estos autores se basan en que, en la biografía de San Ildefonso escrita por Salazar de Mendoza, se localizaba el monasterio desaparecido al norte de la ciudad, cercano al Tajo y en un lugar agreste que se podría identificar con el de la obra de El Greco.

El pintor con esta obra tomó partido en las eruditas discusiones de los historiadores toledanos a favor de quien fue uno de sus más apreciados patronos, al convertir en imagen la hipótesis de éste mientras las de los demás se perdían en palabras, si bien mantuvo cierto carácter de indeterminación al situarlo sobre la nube. La polémica sobre la posible ubicación de este monasterio no fue ni mucho menos un tema baladí a juzgar por la cantidad de información que poseemos al respecto. Si leemos la historia de Francisco de Pisa, nos encontramos con que este historiador cuenta que de ese monasterio tan sólo se sabía a ciencia cierta que estuvo "en el arrabal de Toledo, no lexos de la ciudad" y da todas las posibilidades barajadas en ese tiempo sobre su ubicación. Dos de ellas son especialmente interesantes. Una, porque relaciona a este edificio con el Hospital Tavera, ya que, escribe, «A otros ha parecido que este monesterio aya sido en el propio sitio donde oy está edificado el hospital del cardenal don luan de Tavera, o no lexos del» y, la otra, porque nos habla de «cierta persona curiosa de investigar antigüedades (que) ha querido dezir y divulgar, que a sus manos avian venido unas hojas de papel sueltas de un libro de San Máximo, Obispo que fue de Çaragoça, en las quales se señalava puntualmente el sitio del Agaliense por cuenta de passos que ay desde santa Leocadia la de fuera, y desde S. Pedro el Verde, y desde la propia ciudad hasta el monesterio, todo a pedir de boca como lo tenía traçado esta persona... Mas otras personas muy doctas con quien se avia comunicado, no dan crédito a semejantes cuentos de tan flacos fundamentos» ${ }^{47}$.

Pisa puede estar refiriéndose a Jerónimo Román de la Higuera, quien cita lo escrito por «Magximo Zesar Augustano», cuyas palabras, traducidas del latín, decían que «el rey Atanagildo en la llanura del Arrabal de Toledo edificó un monasterio de la horden de St. Benito" ${ }^{48}$, pero en realidad el

\footnotetext{
47 F. DE PISA, 1605, f. 102 v. . De San Pedro el Verde dice Pisa en otro momento de su historia que está cerca del Tajo, en la parte d ela Vega. La Santa Leocadia «de fuera» es la actual erminta del Cristo de la Vega, donde fue enterrada la Santa. Sobre estos datos, véase T. PÉREZ Higuera, "Iglesia de Santa Leocadia" y "Ermita del Cristo de la Vega", en Arquitecturas de Toledo. Del Romano al Gótico, Toledo, 1991, págs. 205 y 271.

48 J. Román de la Higuera, op. cit., vol. 3 , B.N., Ms. 1287 , f. 3 v. ${ }^{\circ}$.
} 
jesuita se basa fundamentalmente en los papeles que encontró buscando «por los archivos desta ciudad, en la qual ay papeles, y escrituras más antiguas, que en parte ninguna de España» ${ }^{49}$, citando en sus argumentaciones documentos de los siglos XIII, XV y xVI. Su conclusión fue que el monasterio, del que San Ildefonso fue Abad, había que identificarlo con el de San Cosme y San Damián y estuvo en la Vega, cerca de Santa Susana, donde quedaban restos de grandes edificios cuya piedra se había utilizado para la construcción del Hospital Tavera. El nombre de Agaliense se debería a que estuvo en "un tajo o alquería llamada Agalia».

En realidad, Pisa también podía estar refiriéndose a Pedro Salazar de Mendoza cuando criticaba a los que inventaban teorías con poco fundamento, pues el cliente de El Greco cita mucho más explícitamente a Máximo, obispo de Zaragoza, como fuente de autoridad. Este había dicho que el monasterio había estado situado a ciento cincuenta pasos de la iglesia pretoriense de San Pedro y San Pablo. Este lugar lo identifica con el que ocupaban entonces el monasterio de Santa Fe la Real y el Hospital de Santa Cruz, edificios que «cargan sobre el muro de la ciudad" y que «tienen a caballero muy cerca, y debaxo de sí entre el Norte y Poniente, unos edificios desmantelados, donde fue el monasterio de los Predicadores... están en un llano que se haze en la cuesta", y se correspondería exactamente con esa distancia requerida de ciento cincuenta pasos a los referidos edificios. La zona tuvo antiguamente la vegetación, peñascos, árboles, etc. exigidos por la historia para explicar que allí se pudiera haber escondido el santo de la cólera de su padre.

La pintura de El Greco sitúa exactamente el edificio sobre la nube en el lugar que asignaría al monasterio agaliense la historia de Salazar de Mendoza, quien también lo identifica con el de San Cosme y San Damián. Es más, el edificio representado no destaca por su riqueza, lo cual corroboraría también las teorías de este autor, pues critica a aquellos que han querido encontrar huella de la existencia del monasterio en "grandezas de cantería, machinas, conductos, torres, fuentes, obeliscos, pyramides..." - pensamos que es una crítica clara a Román de la Higuera-cuando los monasterios de los godos «eran muy llanos, de tapias humildes, baxos... ${ }^{50}$, que es como lo representa El Greco.

Al igual que había hecho Francisco de Pisa, Salazar de Mendoza da cuenta de todas las teorías barajadas al respecto - al menos seis- lo

49 Idem, f. $148 \mathrm{v} .^{\circ}$.

50 P. Salazar de Mendoza, op. cit., págs. 15-34 
cual no deja lugar a dudas acerca de la existencia de controversias al respecto entre los humanistas toledanos y explica las acusaciones de falta de fundamento entre ellos sobre algunas de las hipótesis planteadas. Una de ellas, la de que estuvo en el pago de Benhalhavia, entre Toledo y Bargas, defendida por el sacerdote Simeón Martínez, que había muerto en 1596, había llegado incluso a convencer al arzobispo Quiroga, quien había dado permiso para edificar allí una ermita ${ }^{51}$.

Puede parecer, leyendo todo lo referente al monasterio Agaliense, así como algunos textos de historiadores de la época, que en algunos casos se comenzaba a desechar las fuentes antiguas escritas como fuente incuestionable de autoridad si no había otro tipo de pruebas para reconstruir la historia de las ciudades. Así lo había hecho bastantes años antes por ejemplo Ambrosio de Morales, al poner en duda la información de los libros antiguos, que decían que Alcalá de Henares no era la antigua Complutum, puesto que no había piedras que corroboraran lo dicho, reflejando así el papel determinante que la arqueología empezó a jugar en esta época para la reconstrucción del pasado ${ }^{52}$. Entre piedras y documentos anduvieron los historiadores toledanos buscando su pasado, y el tema del monasterio debió ser de los que más les apasionó, a juzgar por sus escritos. La pintura de El Greco, refrendando una de las hipótesis, se convierte por tanto en un documento histórico, en una imagen destinada a construir la historia de la Ciudad Imperial en el Renacimiento.

Esta obra sería un buen ejemplo para los hombres de su época de las teorías acerca de la superioridad de la pintura sobre la palabra en la transmisión de la historia. Podríamos citar al respecto, desde Leonardo, hasta al español Gaspar Gutiérrez de los Ríos, quien escribía cómo «las historias pintadas y relevadas, bien se vee que vencen a las escritas en la facilidad y presteza de darse a entender ${ }^{53}$. Pero, sobre este tema hay que señalar sobre todo que el mismo Salazar de Mendoza, tal como recuerda Kagan, «en su biografía de San Ildefonso manifestaba la opinión de que la pintura era un instrumento inapreciable para el estudio de la historia, porque la pintura mueve y levanta más el espíritu que la escritura» ${ }^{54}$.Quizá merezca la pena transcribir la frase completa, pues es como sigue: «Las

\footnotetext{
51 J. ROMÁn de LA Higuera, op. cit., vol. 3, B.N., Ms. 1287, f. 150 v..

52 A. de MORALES, La vida, el martyrio, la invención, lás grăndeżas y translaciones d elos gloriosos niños Martyres san lusto y Pastor, Alcalá, 1568, fol. 35 v. ${ }^{\circ}$.

53 G. GutiérRez de los Ríos, Noticia general para la estimación de las Artes, y de la manera en que se conocen las liberales de las que son mecánicas y serviles. Madrid, 1600, pág. 167.

54 R.L. Kagan, "La Toledo del Greco», en El Greco de Toledo, Madrid, 1982, pág. 65.
} 
pinturas son un muy fuerte argumento, y mayor, que el que se toma de la escritura, si van conformes con la tradición, o con las historias" ${ }^{55}$. La pinturas de El Greco convirtiendo en imagen sus teorías, contribuiría a consolidar esta opinión, pues los textos que hemos ido citando los conocen muy pocos, pero la imagen pintada por El Greco permanece para siempre en nuestro recuerdo después de haber sido contemplada. Al fin y al cabo en el sentido de la vista se cifraba «la grandeza del Universo, porque en el se encierra todo quanto visible ay en el mundo... y todo el, quan grande es, entra a nuestra anima por esta puerta» ${ }^{56}$.

Las obras de El Greco que estamos comentando son imágenes que, de esa manera inmediata a través del ojo, nos transmiten la historia de Toledo que se estaba elaborando en esos años por el grupo de intelectuales con quienes el pintor se relacionó. Por otra parte, si leemos lo que Tirso de Molina escribió unos años más tarde, recreando con la palabra la imagen nocturna de la ciudad de Toledo, «emperatriz de Europa -Roma segunda y corazón de España— », en la que se escribe cómo la noche «había coronado sus altas torres, elevados capiteles, antiguos muros, ventanas y claraboyas, con lo más lucido del cuarto elemento que cebado en el blanco artificio de las abejas, por verse tan alto señorear de la sagrada Vega, creyó estar en su natural centro. Y los esmaltados valles y enriscados montes que la miraban ufanos... juzgaban sus inquietas luces por apretadores, plumas y medallas de diamantes con que adornando su cabeza a imitación de sus hermosas damas, mostraba en su tocado que hasta las cosas inanimadas hermosea el adornarse al uso..." 57 ¿No podríamos imaginarnos la Vista de Toledo pintada por El Greco, si quisiéramos buscar una concreción figurativa de la imagen literaria? Claro que también podríamos citar a este respecto otras palabras de Salazar de Mendoza, que piensa que en Toledo podría haberse dado «la misma contienda que escrive Cicerón, tuvieron los dioses, sobre el sitio, hermosura, y lindeza de Athenas" 58.

Los argumentos elaborados por los historiadores crearon el entramado de las imágenes de la ciudad que pintó el cretense, pero fue su belleza lo que las hizo inolvidables, lo que las convirtió en muy fuerte argumento. Como sabían los contemporáneos, ese era el poder de la pintura.

55 P. Salazar de Mendoza, op. cit., pág. 123.

56 Fray J. DE SANTA MARÍA, Tratado de República, y policía cristiana para Reyes y Príncipes... Madrid, 1615, f. 177.

57 Tirso de Molina, op. cit., pág. 15.

58 P. Salazar de Mendoza, op. cit., pág. d3 v. 
